\title{
Design of a Carburizing Treatment of Steel Base Gear in the Materials Science Course
}

Jiliang Li

Purdue University Northwest, li1919@purdue.edu

Jin Xu

Purdue University Northwest, xu1265@purdue.edu

Nuri Zeytinoglu

Purdue University Northwest, NZ@Purdue.Edu

Jinyuan Zhai

Purdue University Northwest, Zhai33@purdue.edu

Follow this and additional works at: https://docs.lib.purdue.edu/aseeil-insectionconference

Part of the Curriculum and Instruction Commons, Mechanical Engineering Commons, and the Structural Materials Commons

Li, Jiliang; Xu, Jin; Zeytinoglu, Nuri; and Zhai, Jinyuan, "Design of a Carburizing Treatment of Steel Base Gear in the Materials Science Course" (2019). ASEE IL-IN Section Conference. 4.

https://docs.lib.purdue.edu/aseeil-insectionconference/2019/classroom/4

This document has been made available through Purdue e-Pubs, a service of the Purdue University Libraries. Please contact epubs@purdue.edu for additional information. 


\section{Diffusion PDE Application to Carburizing Treatment of Steel Base Gear}

\section{Abstract}

An introductory materials-science course is required in the mechanical engineering curriculum of many universities. This article describes an example effort to incorporate programming, diffusion transfer, heat treatment process and mechanical-property determination as an integral part of the materials-science course instruction. This effort was undertaken in order to give students additional experience in Fick's $1^{\text {st }}$ and $2^{\text {nd }}$ laws and in-depth understanding of physics and mathematics involved in diffusion analysis. We chose to focus on Fick's second law because its applications are not restricted to the materials-science field [1]. As a matter of fact, the same form of parabolic partial differential equation also finds applications in financial derivatives pressure, heat transfer, and soil mechanics consolidation $[2,3]$. For instance, the diffusion coefficients all share the units of $\mathrm{m}^{2} / \mathrm{s}$ [2].

From the perspective of materials science, diffusion refers to an observable net flux of atoms or other species $[1,4,5]$. It depends upon the concentration gradient and temperature. It is vital for the carburization process (Carbon diffusion into steel), determining the proper hardness values not only for surface hardness of gear teeth but also for carbon penetration into specified depths. Students will be required to write a MATLAB program with input parameters of diffusion couple to calculate the atomic flux on the basis of diffusivity and concentration gradient. They are able to predict heat furnace design temperature and time required to heat the metal using error function values and one-dimensional diffusion equation with the specified boundary conditions. This paper focuses on the application of diffusion to material science engineering and provides an example of how diffusion may be adopted in an integrated instruction of materials science instructions.

Keywords: Materials Science, Diffusion, Carburizing, PDE Solutions, MATLAB Programming

\section{Introduction}

Material Science is a required course for both mechanical and civil engineering programs at many universities. The general perception among the students is that it is a theoretical course with few applied engineering problems. Thus, an introductory materials-science course must demonstrate the connection between fundamental principles and their real-life applications. To this end, diffusion, described by a parabolic partial differential equation, was chosen. Relating such a partial differential equation with a materials-science topic could be made more interesting. More specifically, students could be challenged to have a more in-depth understanding of diffusion process through programming and plotting the case-hardening process. 


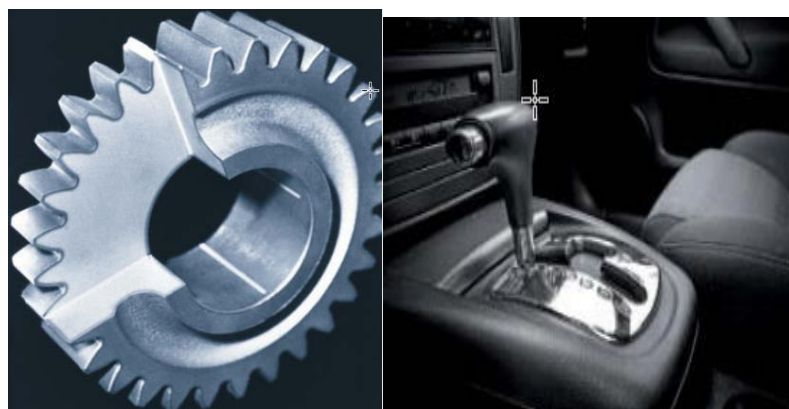

a

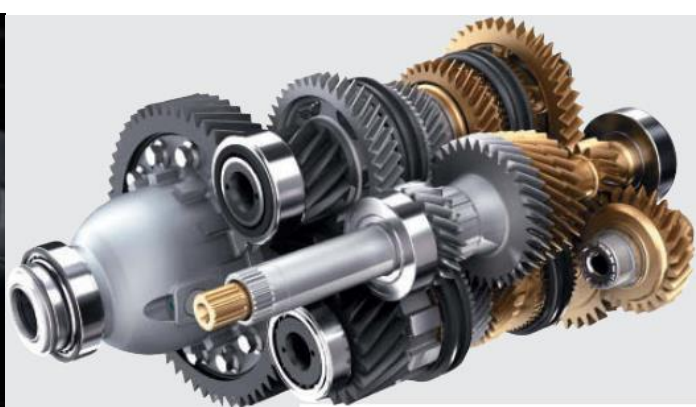

c

Fig1. Case hardened steel gear (after Callister \& Rethwisch, 2014) ${ }^{[1]}$

The photographs above, Fig.1a, on the left, is of a steel gear that has been case hardened wherein its outer surface layer was selectively hardened by a high-temperature heat treatment during which time carbon from the surrounding atmosphere diffused into the surface. The "case" appears as the dark outer rim of that segment of the gear that has been sectioned. This increase in the carbon content raises the surface hardness (Callister \& Rethwisch, 2014), which in turn leads to an improvement of wear resistance of the gear [1]. In addition, residual compressive stresses are introduced within the case region. The purposely induced compressive stresses give rise to an enhancement of the gear's resistance to failure by fatigue while in service. Case-hardened steel gears are used in automobile transmissions as shown in Fig. 1b similar to the one shown in photograph above on the right, Fig 1c.

It is important to help students build the knowledge connections that Fick's $1^{\text {st }}$ and $2^{\text {nd }}$ laws are utilized in the case hardening process. Without highlighting and exposing it as shown in this article, students may not have a complete understanding of the case hardening mechanism involving diffusion PDE process. Computational tools like MATLAB and Excel provide an in-depth calculation power to projects to enhance the understanding of Fick's laws. In this study, students could be assigned to develop a project during the semester about diffusion process. This project can be divided into several phases and spreads out over a period of about two months. Students will be furnished with an introductory handout which consists of short background discussion with a description of the problem as shown below in section III.

\section{Diffusion PDE Fundamentals and Methodology}

Fick's second law describes the dynamic, non-steady state, diffusion of atoms $[1,4,5]$

$$
\frac{\partial c}{\partial x}\left(D \frac{\partial c}{\partial x}\right)=\frac{\partial c}{\partial t}
$$

If the diffusion coefficient $\mathrm{D}$ is assumed to be independent of location $\mathrm{x}$, the following simplified form of Fick's second law can be written as ${ }^{[1,2]}$

$$
D \frac{\partial^{2} c}{\partial x^{2}}=\frac{\partial c}{\partial t}
$$

The solution of equation (2) depends on the boundary conditions and

$$
\frac{c_{s}-c_{x}}{c_{s}-c_{o}}=\operatorname{erf}\left(\frac{x}{2 \sqrt{D t}}\right)
$$

The above equation is a one-dimensional model diffusion of atoms, move only along x direction. Also, it has limitations as follows: 
1) Diffusivity $D$ is independent of the concentration of the diffusing species.

2) The surface concentration of the diffusing species (Cs) is always constant.

The function "erf" is the error function and can be evaluated [1]

$$
\operatorname{erf}(\mathrm{x})=\frac{2}{\sqrt{\pi}} \int_{0}^{x} \exp \left(-y^{2}\right) d y
$$

In equation (4), $y$ is known as the argument of the error function. The "erf" function can be obtained using a spreadsheet program as shown in Fig. 2. For instance, the figure shows the argument and value of the error function encountered in Fick's second law.

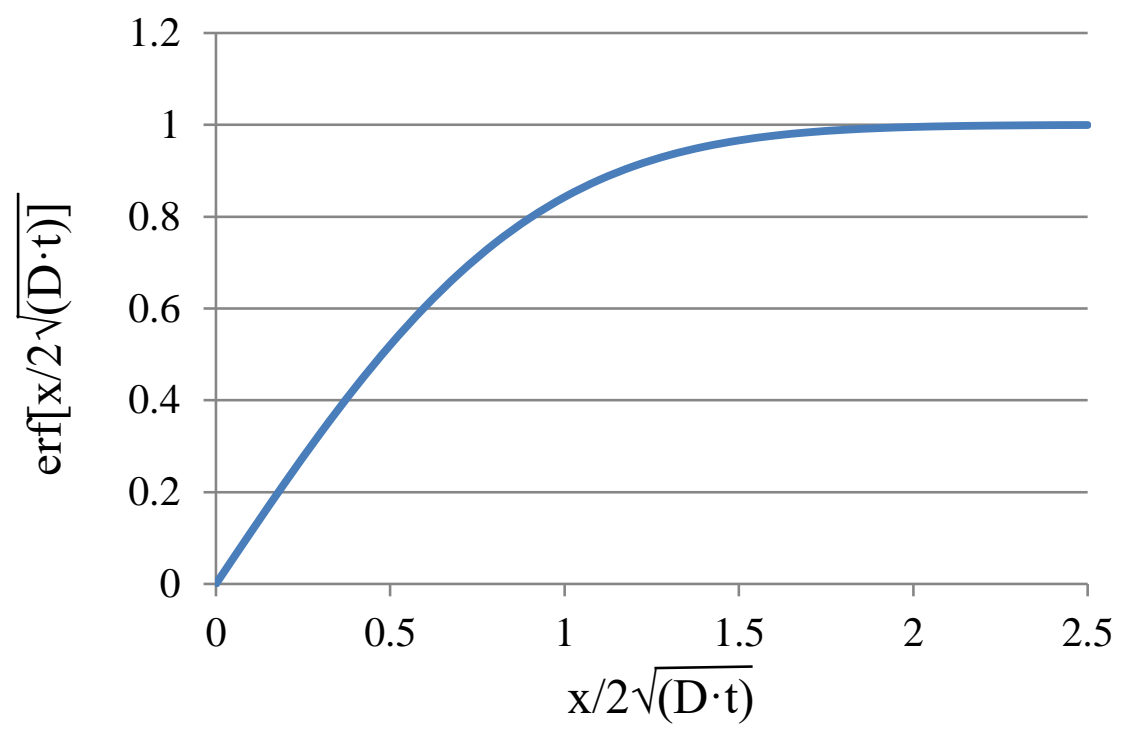

Fig.2 Plot of function "erf" with respect to $\frac{x}{2 \sqrt{D t}}$

\section{Design of Carburizing \& Example}

AISI/SAE 4110 carbon steel gear is to be hardened by carburizing. Herein, SAE stands for Society of Automatic Engineers and AISI stands for American Iron and Steel Institute, respectively. The 41 numbers indicate that alloying elements include chromium and molybdenum [7]. As one of three agencies, AISI is responsible for classification and specification of steels and other alloys. The carbon concentration, in weight percent time 100, is inserted in the last two places for each specific steel, for example AISI 4110 in this case. So herein 10 indicates $0.1 \%$ of carbon weight concentration [1].

In manufacturing environment, steel gears are placed in large quantities and atmosphere and gas carburizing provides $0.1 \% \mathrm{C}$ at the surface of the steel at elevated high temperature. Carbon then diffuses from the surface into the steel. The specification will require the carbon content at a specified depth below the surface. User has to enter the temperature for determining the diffusion coupling parameters ( $\mathrm{C} \rightarrow \mathrm{FCC} \mathrm{Fe}$ or $\mathrm{C} \rightarrow \mathrm{BCC} \mathrm{Fe}$ and using $912^{\circ} \mathrm{C}$ as a transition temperature). The left hand side of the equation can be evaluated easily from equation (3) and the above paragraph explanation and $\sqrt{D t}$ being the unknown where $\mathrm{D}$ is diffusivity $[1,4,5]$ given 


$$
\mathrm{D}=\mathrm{D}_{\mathrm{o}} \exp \left(\frac{-Q}{R T}\right)
$$

where Do is diffusion constant $\left(\mathrm{m}^{2} / \mathrm{s}\right)$, $\mathrm{R}$ the gas constant $8.31 \mathrm{~J} / \mathrm{mol}$ or $8.62 \times 10^{-5} \mathrm{eV} /$ atom. K, T is the absolute temperature $(\mathrm{K})$ and $\mathrm{Q}$ the activation energy for diffusion in $\mathrm{J} / \mathrm{mol}$ or $\mathrm{eV} / \mathrm{atom}$, $\exp ()$ is an exponential function.

Herein numerical methods could be used to solve the governing differential equation (2) and find the concentration values at discrete points (i.e., nodes) of the physical/computational domain. As a matter of fact, the project served as a great case study of incorporating numerical methods into the class because analytical solutions are often based upon unrealistic or simplistic assumptions, and limit the range of applicable problems in reality.

Algebraic equations could be constructed by discretizing the differential equation(s) and their solution is expressed in terms of the concentration at each node. Many different schemes are available for equation discretization. For instance, if diffusion takes place within a solid with uniform concentration of $0.25 \% \mathrm{C}$ due to (constant) surface concentration of $1.2 \% \mathrm{C}$, an explicit or fully implicit scheme could be used to discretize the equation, and obtain the temporal history of the concentration profile. The implicit scheme would yield a linear system of equations, which take either a direct method (e.g., Thomas algorithm since the resultant square matrix is a tridiagonal one) or an iterative method (e.g., Gauss-Seidel method). Given the fact that no students have taken any numerical-analysis course, the explicit scheme was preferred because the resultant algebraic equations would be used in a simple form of substitution and this would add the minimal difficulty to programming. However, care should be exercised when using the explicit scheme, as the numerical stability requirement dictates $\Delta t \leq 0.5 \Delta x^{2} / D$ where $\Delta x$ and $\Delta t$ is the spacing and time step, respectively.

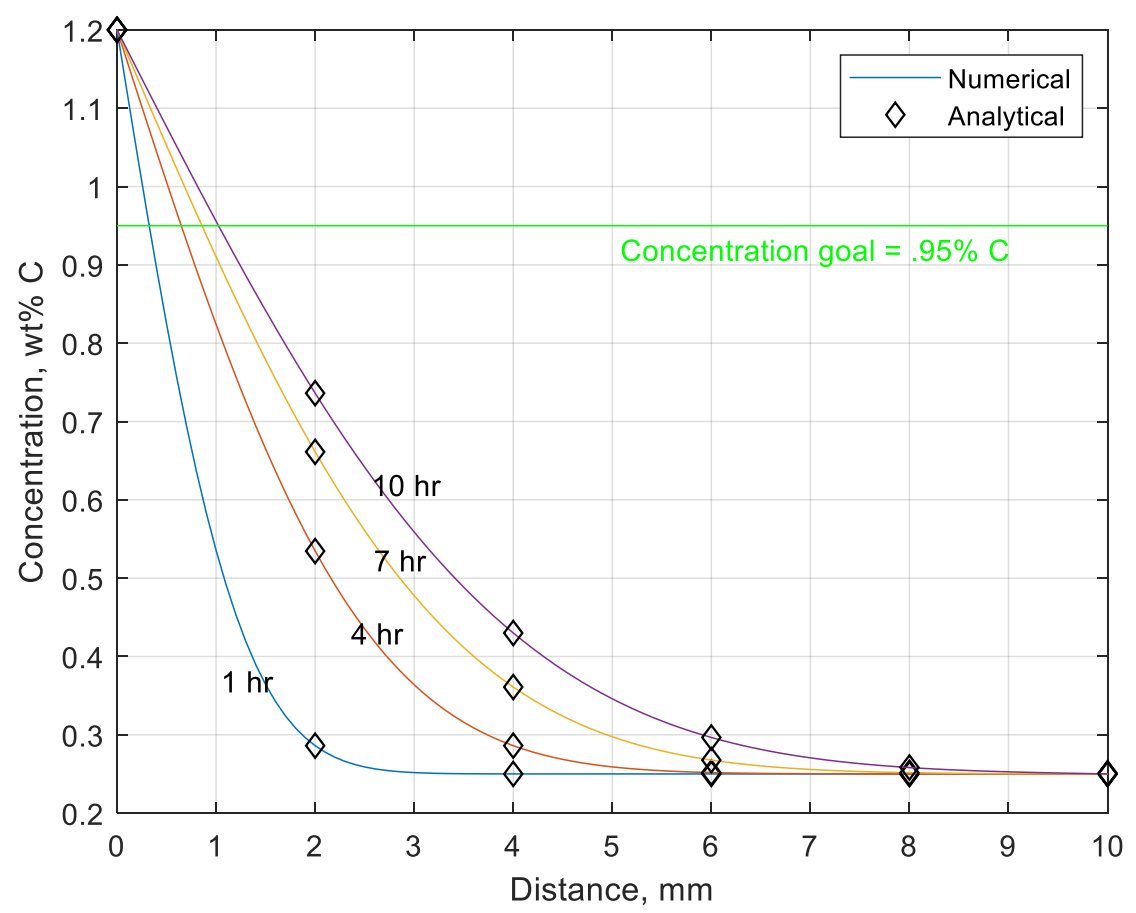

Fig.3 Comparison of numerical and analytical solutions 
Fig. 3 was generated using the explicit scheme with $\Delta t=30 \mathrm{~s}, \Delta x=.1 \mathrm{~mm}$, and $\mathrm{D}=1.29 \times 10^{-10}$ $\mathrm{m}^{2} / \mathrm{s}$. Evidently there is a remarkable agreement between the numerical and (erf-function-based) analytical solutions, which are indicated by continuous lines of different colors and black diamonds, respectively. The change in the concentration exhibits the diffusion process for which four different time instants are specified. Both numerical and analytical solutions could be used to determine, with a given temperature, the time required to achieve a concentration objective, e.g., $0.95 \% \mathrm{C}$, at a certain location.

The following table provides typical combination of temperatures and times of the heat treatment that will provide the optimum properties using $1.2 \% \mathrm{C}$ at the surface and $0.95 \% \mathrm{C}$ at depth of 0.2 $\mathrm{cm}$ below the surface.

Table 1 Heat treatment process temperature vs time relations

\begin{tabular}{|c|c|}
\hline Temperature $\left({ }^{\circ} \mathrm{C}\right)$ & Time (Hour) \\
\hline 900 & 32.3 \\
\hline 1000 & 10.7 \\
\hline 1100 & 4.13 \\
\hline 1200 & 1.82 \\
\hline
\end{tabular}

The exact combination of temperature and time will depend on the maximum temperature that the heat treating furnace can reach, the rate at which parts must be produced and the economics of the tradeoff between higher temperatures versus longer times. Another factor to consider is changes in microstructure that occur in the rest of the material such as grain growth or recrystallization. The other important factors are the cost of operating the furnace increasing the temperature reduces the heat treating cost of the gears and increases the production rate.

\section{Concluding Remarks}

A primary purpose of this article is to show the close ties and applications of parabolic diffusion partial differential equation's applications to materials science learning of materials hardening case study. It is believed that the detailed exposition of the diffusion PDE applications will be beneficial and enhancing students learning of materials science. For example, students will better appreciate the importance of mathematical applications in materials science and engineering courses. Students will also learn to optimize the heat treatment temperature and how the heat processing time may affect the optimum finalized product performance, etc.

The general conclusions of the project can easily be extended to other widely used applications of diffusion such as turbine-blade manufacturing, coating and thin film studies, and creation of plastic beverage bottles. The project discussed above enriches the teaching of material science course, provides the students with marketable skills, and integrates the use of the real-life engineering problems into curriculum. A majority of students indicate that these types of projects are helpful [6]. Presently, efforts are underway by authors at their institution to include more applied problems in the materials sciences and other courses in the engineering curriculum. 


\section{REFERENCES}

1. Callister, W.D. and Rethwisch D. G. (2014), Materials Science and Engineering, An Introduction, Wiley Inc.

2. Li, J., \& Zhai, J. (2017), Teaching/Learning Soil Mechanics with Mnemonics, Intuition, Insight and Inspiration, Paper presented at 2017 ASEE Annual Conference \& Exposition, Columbus, Ohio. https://peer.asee.org/28930

3. Das, Braja M and Sobhan Khaled, (2018), Principles of Geotechnical Engineering, $9^{\text {th }}$ Edition, CENGAGE Learning.

4. Shackelfford, James F. (2015) Introduction to Materials Science for Engineers, $8^{\text {th }}$ Edition, Pearson.

5. Verhoeven, D. John (1975) Fundamentals of Physical Metallurgy, John Wiley and Sons, Inc.

6. Vavrek S., Neuhold L., and Prim Z. (2018) “Artificial Organs" Unpublished Paper Manuscript, Department of Mechanical and Civil Engineering, Purdue University Northwest, Westville, Indiana.

7. 41XX Steel, https://en.wikipedia.org/wiki/41xx_steel, last accessed February 18, 2019 